\title{
A CIDADE INDUSTRIAL E SEU REVERSO: AS COMUNIDADES UTÓPICAS DA INGLATERRA VITORIANA
}

\author{
Cristina Meneguello*
}

Seus pés já caminharam no passado?

E pelos verdes montes da Inglaterra

Seus pés já caminharam no passado?

Nos apraziveis prados da Inglaterra

O cordeiro de Deus foi avistado?

William Blake ${ }^{1}$

\begin{abstract}
RESUMO
O presente artigo procura dimensionar o debate sobre as "cidades utópicas", que comumente confere aos experimentos ingleses do século XIX uma continuidade com as utopias clássicas e certa dose de ineficácia e ingenuidade, procurando ver a positividade contida nas utopias habitacionais. Centrando-se na experiência britânica iniciada com owenismo, passando pelas vilas industriais planejadas e finalizando no ideal da cidade jardim, busca-se ver a comunidade ideal como o reverso da organização industrial da cidade e como uma proposta histórica de ocupação do espaço que é definitiva para a experiência urbana posterior.

Palavras-chave: história da cidade e do urbanismo, utopia, cidades e vilas industriais na Inglaterra do século XIX.
\end{abstract}

\footnotetext{
ABSTRACT

This article aims at giving new dimension to the debate on "utopian villages", that commonly understands the British experiments of the nineteenth-century as a continuation of the classical utopias tinted with a hint of inefficacy and naiveté. On the contrary, this article intends to search for the positive aspects of such utopias. Centering on the British Universidade Estadual de Campinas (Unicamp).

1 BLAKE, W. Prosa e poesia selecionadas. Tradução e prefácio de Paulo Vizioli. São Paulo: Nova Alexandria, 1993. Edição bilíngue, p. 101.
} 
experience of Owenism, studying the model villages and ending on the garden cities, the ideal community is seen as the opposite of the industrial urban organization and as a historical definition of occupation of space, fundamental for urban planning.

Key-words: history of city and urbanism, utopia, industrial villages on Nineteenth Century Britain.

Quando Blake, em resposta ao Paraíso de Milton, reafirmava estar no solo inglês a possibilidade de reencontrar o passado - os pés que caminharam no passado são os de Cristo, segundo a lenda de que Jesus teria visitado a Inglaterra, logo após a sua Ressurreição, acompanhado por José de Arimatéia -, de certa forma, unia a ode ao passado com a constatação do progresso desenfreado. Afinal, o poema prossegue fazendo referência aos dark satanic mills, cantados por Milton, à industrialização e ao racionalismo mecânico, tão avessos à literatura da sensibilidade.

\author{
E o Semblante Divino iluminou \\ As névoas destes morros e caminhos? \\ Jerusalém foi construída em meio \\ a estes negros Satânicos Moinhos? \\ (...) \\ Minha espada não vai dormir na mão \\ Nem no campo mental eu cesso a guerra \\ Até erguermos enfim Jerusalém \\ Nesta verde e aprazível Inglaterra. \\ (BLAKE, 1993)
}

De modo geral, os textos que tratam da questão da utopia como uma localização possível de uma boa sociedade aceitam uma organização "imaginada" a partir de um marco zero. Destarte, estabelecem uma "marcha para trás", num retrocesso irrefreável que pode chegar ao próprio Jardim do Éden como a primeira utopia humana. As paradas consagradas dessa "marcha" usualmente ocorrem na República, de Platão, na Utopia, de Thomas More, ou na Cidade do Sol, de Tommaso Campanella, para culminar nas utopias socialistas do século XIX ou mesmo em cidades imaginadas do século XX, como a cidade radieuse, de Le Corbusier, ou a industrial, de Tony Garnier.

Em uma lista interminável, esses "locais" possuem em comum sua essência - são não-lugares ou bons lugares (eu-topos) - e o projeto de co- 
munidade ou sociedade ideal, cujos princípios são refletidos na organização espacial.

Três utopias do período moderno, porém, afirmam definitivamente no campo literário e, mais importante, no pensamento político a descrição de um local de vida aprazível e de governo possível: Utopia, de Thomas More (primeira edição em latim, 1516); A Cidade do Sol, de Tommaso Campanella (primeira edição em latim, 1623); e Nova Atlântida, de Francis Bacon (primeira edição em inglês, 1627); todas exemplares do pensamento humanista do Renascimento e, igualmente, todas presentes na recuperação empreendida pelos vitorianos.

Em assumido diálogo com o texto de Platão - “(...) ao Estado de Platão vou-me igualar, ou superar, pois ao que era só palavra, infundi vida"” - Utopia, de More, descreve uma comunidade ideal em "lugar-nenhum", conforme a palavra criada por More. Dividida em duas partes, a obra inicia com um diálogo criticando as condições econômicas e sociais da Europa contemporânea, especialmente a guerra, os cercamentos - que tornaram os carneiros "devoradores de homens" (p. 27) -, a opressão, os impostos e as leis injustas contra os pobres. Dessa parte do diálogo, More participa com um tom algo incrédulo, operando um deslocamento entre o autor, o More personagem e Rafael Hitlodeu, o viajante português que visitou, após se perder do grupo de Américo Vespúcio, a ilha de Utopia. Sua viagem é descrita no Livro II, assim como a comunidade ideal, sua religião, governo, educação, economia, guerras, leis e costumes: a propriedade privada inexiste - como afirmara Hitlodeu no Livro I, "não vejo como se possa pensar em justiça ou prosperidade verdadeiras enquanto existir a propriedade privada" (MORE, 1993, p. 57); o ouro é desprezado, "utilizam a prata e o ouro para a fabricação de (...) urinóis. Também usam correntes e grilhões de ouro para prender os escravos e todos os que praticam crimes realmente graves são forçados a usar anéis de ouro nas orelhas e nos dedos (...)" (MORE, 1993, p. 92); e há uma vaga tolerância religiosa "todos ficam livres para imaginar a sua divindade da maneira que melhor lhes aprouver (MORE, 1993, p. 154); afinal, More escreveu antes da Reforma.

Desde sua publicação, Utopia foi interpretada de diferentes maneiras como uma sátira contra a corrupção de sua época, como uma visão cristã

2 MORE, T. A utopia. In: MORE, T. Os pensadores. São Paulo: Martins Fontes, 1993. p. 
de um paraíso para humanistas (poupados das atividades mais pesadas) ou até mesmo, a partir do século XIX, como um manual comunista. De forma geral, Utopia ataca as condições desiguais da Europa de seu tempo e descreve um Estado ideal baseado na razão. O espaço-objeto da ilha é eternamente assegurado pelas atividades temporais de seus cidadãos. A forma urbana é clara e um artefato fruto da vontade humana (o rei Utopos cria a ilha artificialmente, reforçando seu caráter de isolamento). Embora More descreva apenas a capital - Amaurot - todas as demais 54 cidades da ilha são semelhantes: "nelas todos falam a mesma língua, têm os mesmos hábitos e vivem sob as mesmas leis e instituições. Um mesmo projeto orientou a construção de todas (...) quem conhece uma de suas cidades, conhece todas" (MORE, 1993, p. $65,68)$. O aspecto de regularidade e repetição das cidades de Utopia será resgatado posteriormente por outras narrativas utópicas, assim como a importância do cultivo do solo e o uso dos bens em comum em um mercado central. As ruas são alinhadas com casas de dois andares e um jardim ao fundo. Por sistema de sorteio, a cada dez anos os habitantes deixam suas casas e mudam-se para a casa de seus vizinhos. Como não há posses, todo o mobiliário e conveniências necessárias ficam na casa; do mesmo modo, cada habitante deve, por dois anos, trabalhar no campo, a base de sustento da cidade. Mas toda essa organização é mantida com rigor; os criminosos são punidos com a escravidão ou o degredo e a política deve apenas ser debatida no espaço do Senado, sob pena de morte. ${ }^{3}$

A Cidade do Sol, de Campanella, segue o padrão de cidade radial, em progressivas muralhas, nas quais, nos moldes enciclopédicos, repousa todo o conhecimento da comunidade na forma de desenhos usados para a instrução das crianças. A narrativa serviu de inspiração imediata para a criação de Palmanova, na Itália, próxima a Veneza, e para a Cosmópolis, de Medici. ${ }^{4}$ O Sol é símbolo do calor, da força, da virilidade, da autoridade e

3 F. Choay parece desconsiderar essa questão ao comparar a Inglaterra (e a Europa de maneira geral) à ilha de Utopia, mencionando que a aplicação da pena de morte vigia apenas nos espaços "reais". Cf. CHOAY, F. A regra e o modelo: sobre a teoria da arquitetura e do urbanismo. São Paulo: Perspectiva, 1985. p. 166.

4 Cosimo I de Medici concebeu a cidade fortaleza de Portoferraio, na ilha de Elba, a ser chamada de Cosmópolis (cidade do mundo e cidade de Cosimo). ROSENAU, H. The ideal city. London: Routledge/Kegan Paul, 1959. 
do sexo masculino; as palavras de ordem são poder, sabedoria e amor. Sete torres de fortaleza, cada qual com o nome de um planeta, protegem a cidade. Há, como em Utopia, a distribuição dos bens em um mercado comum. Na Cidade do Sol, porém, não existe a vaga tolerância religiosa observada em Utopia, visto que os planetas regem a vida das pessoas e até a escolha das uniões, numa espécie de eugenismo cosmológico (mas não de "ocultismo", como muitas vezes afirmado, visto que a astrologia nada mais é que a manifestação de Deus na natureza).

Já Bacon, ao imaginar sua ilha ideal de Bensalem em Nova Atlântida, recorre ao uso da ciência e da idéia da perfectibilidade humana e da sociedade de modo geral. A Casa da Ciência e a Casa de Salomão são os locais mais importantes da ilha, nos quais se desenvolve o conhecimento. A utopia inacabada de Bacon prevê, diferentemente das anteriores, a propriedade privada, o casamento e a família como bases da sociedade. Notavelmente, os sábios são o coração da sociedade e suas descobertas científicas alimentam a comunidade: navegação, cirurgia, máquinas voadoras, uso da energia hidráulica etc., na busca de ampliar o domínio do homem sobre a natureza. Buscam prolongar a vida, curar doenças, alterar os frutos e as flores, realçando sua cor e seu sabor, cruzam espécies diversas para criar híbridos, obtêm luz de diversos corpos, gravam sons, criam autômatos, navegam por debaixo d'água e voam pelos céus. ${ }^{5}$ Certos comentaristas argumentam que Bacon, de certo modo, inaugurou a utopia da ficção científica ao dar poderes máximos à ciência perante a realidade. ${ }^{6}$ De todo modo, os experimentos por ele cuidadosamente descritos foram ridicularizados por Swift em Viagens de Gulliver, numa reação à ciência como a base de toda a harmonia possível. ${ }^{7}$

No século XVIII, a tradição das descrições utópicas prossegue e, simultaneamente, muda. Conforme observa Baczko, ${ }^{8}$ a cidade revolucioná-

5 BACON, F. Nova Atlântida. Lisboa: Minerva, 1976. p. 62-73.

6 JEAN, G. Voyages en utopie. Paris: Gallimard, 1994. p. 51.

7 Ao visitar a cidade de Lagado e sua academia, os homens sábios são retratados como idiotas em experimentos absurdos, como guardar raios de sol em vidros ou construir casas começando pelo telhado. SWIFT, J. Viagens de Gulliver. Rio de Janeiro: W. M. Jackson, 1964. (Clássicos Jackson, v. 31), p. 161-202.

8 BACZKO, B. Lumières de l'utopie. Paris: Payot, 1978. Critique de la politique, cap. 5. 
ria é monumento e cenário, obcecada pelo simbolismo do centro, isomórfica em relação aos projetos utópicos que a antecederam. A cidade não se reduz a uma cópia atenta de modelos anteriores, mas é testemunho da imaginação histórica em busca da conquista do espaço urbano, no qual o urbanismo e a arquitetura podem realizar as promessas de um quadro social, das cerimônias e das festas revolucionárias. Em sua obra, Baczko oferece várias descrições das cidades imaginadas no século XVIII, notando em todas pontos em comum. Sévariade é descrita por D. Veiras em Voyages imaginaires (editada em Amsterdam, 1787): capital do reino de Sevarambes, é "a mais bela cidade do mundo", com número limite de habitantes, protegida por uma imensa muralha e concebida sobre um plano racional e rigorosamente aplicado, que faz dela também a cidade mais regular do mundo. Gasta-se uma hora para ir da periferia ao centro, onde estão o palácio, o templo do sol, o anfiteatro para as festas públicas e o lago, um dos principais ornamentos da cidade. O palácio em mármore branco possui portas enfileiradas na mesma direção, para que todo o palácio possa ser visualizado de um lado a outro. A entrada principal, colossal, forma um portal com 44 colunas de bronze e todas as normas de arquitetura são bem observadas. Conforme conclui Baczko, as utopias urbanas do século XVIII aliam o simbólico à idéia da transparência total da cidade e, ao mesmo tempo, da sociedade. Ambas são legíveis em todos os seus níveis e cada parte dá a conhecer o todo.

Baczko ainda comenta que, se o autor de Sévariade conhecesse o jargão urbanístico, diria que o espaço urbano da cidade está disposto segundo a "unidade fundamental de habitação" - a "osmasie" -, uma unidade tanto de mensuração quanto de valoração socioeconômica dos habitantes, que, mais uma vez, não possuem propriedade privada, trabalham em comum e levam o fruto de seu trabalho para um armazém geral onde tudo é dividido. As osmasies em que vivem são habitações quadradas de quatro portas, quatro andares e construídas em mármore ou pedra branca, com um grande corredor entre as construções. Cada uma forma um quarteirão fechado em si mesmo (um jardim forma-se no corredor interno) e aberto para a cidade. A cidade é concebida para o bem-estar de seus habitantes: como faz calor, há fontes, sombras e verde por todas as partes. Ecoando Utopia, todas as outras cidades dos Sevarambes são como a capital. Os jardins estão nas ruas, sustentados por construções de ferro, e dentro das habitações. 
Um sistema engenhoso permite a circulação e a abundância de água, evitando incêndios e trazendo frescor, além da possibilidade de lavar as ruas. ${ }^{9}$

O século XIX terá à sua disposição as narrativas utópicas anteriores, às quais fará referência com freqüência. Ao mesmo tempo, o caráter de experimentação será determinante para a reconceitualização da utopia. Ao lado de narrativas literárias, planos a serem executados são lançados, propagandeados em jornais (como os paralelogramos de Robert Owen ou o Allons en Icarie, de Cabet). Procuram realizar, a partir do local, uma ampla transformação social.

Pode-se afirmar que o olhar transformador da cidade, existente em favor de uma comunidade em pequena escala, que valoriza simultaneamente o homem e o trabalho, possui ligações evidentes com as concepções de Ruskin e de Morris para uma sociedade futura. Não se tratava, porém, de impossibilitar o futuro pelo apego ao passado, mas de transformar o passado em um tempo futuro. Desse modo, a valorização do passado e de seus vestígios e ruínas torna-se indissociável de uma nova comunidade baseada em princípios solidários.

Nas utopias, o retorno (ou avanço) rumo à Idade de Ouro lida com uma memória que não é individual, mas que pertence à memória da História, assim reconstituída, na inflexão, na transformação e na seleção que faz $\mathrm{o}$ ato da memória. Esse passado nunca foi de fato conhecido,

...seu poder evocador é o de um modelo, de um arquétipo, modelo e arquétipo a que a emergência fora do tempo decorrido parece por definição dar um valor suplementar de exemplaridade... Como quer que seja, a cada modo de sensibilidade - ou de pensamento - político corresponde, assim, uma cera forma de leitura da História, com seus esquecimentos,

9 Note-se aqui a importante relação com a água, não apenas presente em outros tratados muito anteriores, como na descrição da cidade renascentista de Sforzinda por Filarete, na qual um reservatório central de água podia ser aberto periodicamente para lavar todas as ruas, em ligeiro declive em relação ao centro (Cf. FILARETE. Cadernos: clássicos do urbanismo. Tradução de Ivone Salgado e Mário Henrique Simão d'Agostinho. Campinas: Curso de Especialização em Urbanismo, FAU-Puccamp, [19-]. Cópia mimeog. Ou seja, une-se os primórdios das concepções de higiene e circulação ao pavor dos incêndios tão presentes nos séculos XVI e XVII. Cf. SENNETT, R. Carne e pedra - o corpo e a cidade na civilização ocidental. Rio de Janeiro: Record, 1997. Capítulo "Corpos em movimento". 
suas rejeições e suas lacunas, mas também com suas finalidades e devoções, fonte jamais esgotada de emoção e de fervor. ${ }^{10}$

Girardet analisa especificamente o caso francês, em que a busca por mitos no passado leva, já na segunda metade do século XVIII, ao estado de natureza e ao passado que contém a dupla força da pureza e da inocência, assim como da amizade, da solidariedade e da comunhão. Na recuperação política que se faz do "mundo de dantes", imperam os modelos de organização coletiva e, no caso da recuperação do passado medieval, uma evidente reação ao individualismo liberal e ao estadismo totalitário. Para Rousseau, a imagem da cidade antiga fundamenta o Contrato social e a agitação e a degeneração da vida na cidade ganham contornos exemplares. Conforme observa Raymond Williams, em Emílio, de Rousseau, a cidade concentra as energias fundadas nas leis de mercado; é a "sentina de todos os vícios", abismo da espécie humana, o amontoamento da canalha. ${ }^{11}$

No pensamento político, permanece o duplo movimento de carregar o passado como um peso e de, ao chorar sua perda, suspirar pelo seu retorno. A vontade política, não de uma volta, mas de um renascer do passado explica a mitologia política da Idade de Ouro, que pode estar presente tanto atrás como à frente na linha do tempo.

As utopias literárias ou, nas palavras de Choay, as "organizações textuais arquetípicas"12 são continuamente reiteradas pela cultura ocidental e, desse modo, fica evidente sua funcionalidade em que a estrutura da versão canônica é acrescentada de variantes, mas mantida em sua integridade. Corre-se o risco de anacronismo quando se classifica sob o mesmo prisma momentos tão diversos como o século XVI, de More, as utopias socialistas, as cidades projetadas por patrões industriais, as cidades-jardim do século XIX e a cidade ideal de Le Corbusier. Ainda assim, são propostas de sociedades ideais, cuja perfeição é refletida na disposição urbana; assim, nem o caráter de impossibilidade nem o de fantasia conceituam a utopia, mas, no que tange ao século XIX, a conceituação de experimentação

10 GIRARDET, R. Mitos e mitologias políticas. São Paulo: Cia. das Letras, 1987. p. 98.

11 WILliAMS, R. O campo e a cidade na história e na literatura. São Paulo: Cia. das Letras, 1990. p. 70.

12 CHOAY, op. cit., p. 239. 
utópica com objetivo de ser, dentro de uma dada sociedade, um germe de mudança que pode ou não afetar toda a sociedade.

A (falsa) sensação de que é possível entender os temas do urbanismo utópico no século XIX como um bloco pode derivar do fato de a própria utopia não se compreender como delimitada pelo tempo, de ser atemporal. Ao mesmo tempo, os experimentos do século XIX são sempre apresentados como "imaginados" e em seqüência direta, por exemplo, com as utopias renascentistas. Mas, diferentemente do que ocorria no Renascimento, quando o espaço ideal localizava-se sempre no Novo Mundo (terras mágicas e longínquas que a literatura das viagens e navegações não cessava de narrar), as utopias do século XIX não possuem a priori um espaço dado, um local, pois mesmo quando imaginadas a partir de um local conhecido, ocorrem em um momento não existente, como a Londres do futuro de William Morris em seu News from Nowhere, de 1891.

Novas de nenhum lugar - a utopia vitoriana recita a linhagem que a antecede. Repete fórmulas (línguas entendidas por todos os povos, divisão de tarefas e do fruto do trabalho, cidades com conformações ideais, igualdade nas construções, desapego ao dinheiro etc.) e assim estabelece, ela mesma, uma linha de continuidade em relação ao passado.

"Senti-me como se estivesse vivendo no século XIV": essa é a impressão do Morris-narrador em News from Nowhere. ${ }^{13}$ Morris recria, na Londres do futuro, os ideais de trabalho e arte que acreditava existirem no século XIV, data a que faz menção em várias partes do texto (p. 46, 53, 61 e 226). Seu anfitrião, o rapaz Dick, um barqueiro que o leva por toda a Londres do futuro e também Tâmisa acima, traja "roupas [que] não eram em nada parecidas com as modernas roupas de trabalho, mas [que] ficariam bem em um quadro da vida no século XIV: de tecido azul escuro, simples, mas de bela traja, sem nenhuma mancha" (p. 46) - ficariam igualmente bem em um quadro pré-rafaelista. A utopia no tempo, como a classificaria Szacki, se dá rumo ao passado. ${ }^{14}$

Após a grande revolução que levou ao fim do domínio da máquina e da exploração do trabalhador (que para Morris ocorreria em 1953, con-

13 MORRIS, W. News from Nowhere and other writings. London: Penguin Books, 1993 (1890). Introdução e notas por Clive Wilmer, p. 61.

14 SZACKI, J. As utopias ou a felicidade imaginada. Rio de Janeiro: Paz e Terra, 1972. 
forme a primeira edição do livro, e 50 anos mais tarde, na edição seguinte), os homens vivem em uma sociedade na qual os ideais comunitários vigoram e o prazer e o trabalho são indissociáveis. Não há pobres, não há propriedade, o Tâmisa é limpo, não há fábricas, mas locais de convívio para pessoas que querem trabalhar juntas, e a idéia do dinheiro ou de ser pago por realizar alguma função causa espanto ou arranca gargalhadas dos habitantes da Londres do futuro. ${ }^{15}$

A cidade reflete os princípios dos que nela habitam: há pontes mais belas que a Ponte Vecchio em Florença; a arquitetura une "as qualidades do gótico da Europa do Norte às do sarracênico e bizantino, sem contudo copiar nenhum desses estilos" (p. 48 e 62). O século XIX, que Ruskin já chamara de "Idade das Trevas" em notável inversão ao termo utilizado na Idade Média, ${ }^{16}$ é julgado pelo tribunal da história. Dick comenta: "Vi nos livros do século XIX (...) a estupidez daquela época, que desprezava todos que podiam usar suas mãos!". ${ }^{17}$ Quando Morris-narrador ganha um lindo cachimbo (visto que nada pode ser comprado) e se compraz com a arte que preside os menores objetos do cotidiano (MORRIS, 1993, p. 80-81), vem a saber que "a arte, como costumava ser chamada, não tem esse nome entre nós, porque se tornou uma parte necessária do trabalho que todo homem produz", explica seu anfitrião (p. 160). "O trabalho é um prazer que tememos perder, e não uma dor" (p. 122).

Na narração utópica do século XIX, as especificidades são imediatas e dialogam com o momento de rápida desaparição dos traços da cidade, do nascimento da questão da preservação do patrimônio, da redescoberta do passado e das raízes. Vale recuperar a historicidade do estudo da utopia urbana que surge no bojo da Revolução Industrial - tanto a cidade projetada para os operários pelo seu patrão, em contraposição aos terrores da vida nos bairros operários, como as cidades-comunidades, em que se poderia realizar o sonho do socialismo e do viver comunitário.

Inspiradas por narrativas modernas, as comunidades dos socialistas utópicos e as cidades dos industriais vão se definir como dependentes

15 MORRIS, op. cit., p. 50.

16 Apud LÖWY, M.; SAYRE, R. Revolta e melancolia - o romantismo na contramão da modernidade. Petrópolis: Vozes, 1995. p. 202.

17 MORRIS, op. cit., p. 58. 
da produção industrial e localizar-se nos arredores das grandes cidades, com as quais estão em constante relação. Georges Jean divide as possibilidades da utopia em quatro: estão "antes da História", "do lado de fora da História", "dentro da História" ou "após a História". ${ }^{18}$ A utopia que antecede a História remete ao Jardim do Éden, a uma Idade de Ouro que antecede a história da humanidade, conforme descrita por Hesíodo em Os trabalhos e os dias. Ou seja, uma época sem vicissitudes nem necessidades, em que o homem não necessitaria do suor de sua fronte para obter seu sustento. A utopia "fora da História" faz referência a todas as narrativas que antecedem o final do século XVIII, quando, como visto, concebe-se no Novo Mundo a localização da cidade utópica. As utopias de "após a História" são similares à empreendida por Le Corbusier e outros seguidores do movimento moderno, em que a idéia de um estilo e de uma prática internacionalizados ultrapassaria as fronteiras geográficas e temporais, em busca de uma realidade total para a raça humana.

Restam, assim, as utopias do século XIX - as que estão na história. Jean aceita uma definição semelhante às de Szacki e Manheim, ${ }^{19}$ em que as utopias ocorrem com um plano de realização concreta que inclui a transformação da sociedade dentro das próprias condições dessa sociedade. Tais utopias, entretanto, mesmo quando efetivamente construídas e postas em funcionamento, são frequientemente retratadas como fracassos, pois a data de sua extinção é assinalada e utilizada para aferir a possibilidade, ou não, da concretização do sonho utópico. Os experimentos do século XIX podem ser compreendidos como "o reverso" da cidade industrial e, simultaneamente, como parte obrigatória da mesma, sem a qual ela não pode ser definida.

A narrativa dos experimentos utópicos na Inglaterra do século XIX geralmente se inicia com Owen e sua experiência em New Lanark (Benevolo, Choay, e mesmo Jean o fazem, para mencionar alguns), considerada a primeira tentativa de reconstruir o ambiente para determinar a sorte dos indivíduos visando a uma sociedade melhor. Robert Owen, tendo se casado com a filha de David Dale (1771-1858), o fundador de New Lanark, após

18 JEAN, G. Voyages en utopie. Paris: Gallimard, 1994. p. 12.

19 MANHEIM, K. Ideologia e utopias. Rio de Janeiro: Zahar, 1972. 
trabalhar para ele como administrador, comprou a fábrica e as moradias de operários em 1799, as quais submeteu a importantes alterações de acordo com as teorias de Thomas Spence (1750-1814), de que vale a influência do ambiente e de que o self-made-man é uma abstração.

Owen estabeleceu melhor remuneração, horário de trabalho e casas para os operários de New Lanark e criou, em 1816, o "Instituto para a Formação do Caráter", em que a filantropia e o ideal educacional se uniam numa proposta que poderia ser ampliada para contemplar as Poor Laws. Para proporcionar emprego para os trabalhadores sem barrar o progresso ilimitado, Owen sugeriu seu paralelogramo, divulgado nas páginas dos jornais londrinos em 1817. Assim, a comunidade ideal de Owen se distribuiria em prédios que abrigariam cerca de 1200 pessoas, rodeados por cerca de 1000 acres, divididos em paralelogramos. O prédio central possuiria, à direita, a cozinha geral, refeitórios, escolas para crianças pequenas, gabinetes de leitura e local para cultos. À esquerda, haveria a escola para as crianças mais velhas e salas para adultos, além da biblioteca. Os três lados de cada um dos quadrados habitados seriam alojamentos para casados, obrigatoriamente com quatro cômodos (para o casal e duas crianças que, conforme indicavam os relatos médicos da época, deveriam dormir separados se fossem de sexos diferentes). O quarto lado do quadrado abrigaria crianças com mais de três anos que excedessem o número de dois filhos em uma família. Em uma extremidade ficaria a enfermaria e, na outra, um prédio para forasteiros que viessem visitar a família ou os amigos.

Nesse sistema, as funções estavam também divididas por sexo: as crianças deveriam comer no refeitório e dormir em seus próprios dormitórios "sendo que os pais podem, é claro, vê-las e falar com elas durante as refeições e em outros momentos apropriados (...), pois as crianças devem ser instruídas a não adquirir os maus hábitos de seus pais". ${ }^{20}$ As mulheres deveriam, em primeiro lugar, cuidar das crianças; em seguida, cultivar as hortas; poderiam trabalhar na manufatura, mas não mais do que quatro a cinco horas por dia; por fim, deveriam fazer as roupas, cuidar da cozinha e

20 OWEN, R. A view of a plan of the agricultural and manufacturing villages of unity and mutual co-operation. Morning Post, 7 Aug. 1817. (Working Class Movement Library, Salford, Reino Unido). 
dos dormitórios e supervisionar a educação das crianças na escola. As crianças mais velhas teriam funções semelhantes. ${ }^{21}$

As teorias de Owen influenciaram bastante o movimento das cooperativas. Advogando o socialismo comunitário e rejeitando a noção de luta de classe como meio para a mudança social - pois a sociedade seria transformada por meio de comunidades experimentais -, Owen não encarava as comunidades como ocasionais ou ineficientes, mas como um modo de pôr em prática uma teoria coerente de transformação social. Um sentido de comunidade seria o elemento das relações humanas, ausente no início do século XIX na Inglaterra, a ser recuperado. ${ }^{22}$ No mais, segundo seu objetivo educacional de "formação de caráter", Owen propunha um ambiente favorável longe das influências corruptoras da sociedade. Tal construção poderia se dar imediatamente, sem recorrer a "estágios"; a seus contemporâneos, a idéia parecia radical, mas possível; parecia nova, mas não inédita, e, assim, teve campo para aceitação.

Os planos de Owen de educação e reforma no trabalho fabril amadureceram entre 1816 e 1820, baseados na melhoria de condições de trabalho e de vida que concebera para New Lanark. Em seu Report to the Committee of the Association for the Relief of the Manufacturing and Labouring Poor, de 1817, ele diagnosticou a questão do desemprego, sugerindo como solução as comunidades auto-suficientes. Seu plano estabelecia aldeias de cooperação (villages of co-operation) que incluiriam todas as classes e não apenas os pobres. Tal versão amadureceu em seu Report to the County of Lanark (1820), cujo subtítulo o dizia claramente: "Um plano para diminuir a tensão pública e eliminar o descontentamento, ao proporcionar emprego permanente e produtivo aos pobres e às classes trabalhadoras, sob arranjos que fundamentalmente elevam seu caráter e melhoram sua condição, diminuindo os gastos com produção e consumo para criar mercados coextensivos à produção. ${ }^{23} \mathrm{Ou}$ seja, o plano que ini-

21 Note-se a impressionante semelhança entre essa descrição e a narrativa de Eugene Sue em seu $O$ judeu errante, algumas páginas adiante.

22 HARRISON, J. Robert Owen and the Communities. In: HARRISON, J. Robert Owen industrialist, reformer, visionary 1771-1858 - four essays to mark the second centenary of the birth of Robert Owen on May 14th 1771. London: Robert Owen Bicentenary Association, 1971.

23 OWEN, op. cit., p. 250. 
cialmente servira para alívio do desemprego evoluiu para uma reorganização da sociedade.

Anteriormente, em seu A sketch of some of the errors and evils, ${ }^{24}$ Owen já estabelecera os critérios de divisão entre a cidade industrial existente e sua comunidade ideal, também existente: as questões do desemprego, do número limitado de habitantes e do estabelecimento de funções coordenadas entre a agricultura e a indústria. Owen prossegue com a comparação entre as duas formas de habitar: de um lado porões, de outro, casas ornamentadas distribuídas em grandes quadrados; de um lado sujeira, fumaça e ausência de um lugar belo para fixar a vista, de outro, jardins, ar puro e campos para serem admirados; de um lado, cada família provê alimentos ao mercado, de outro, a produção destinada a prover a própria família, e onde, em comunidade, seis pessoas cozinham para 100; de um lado, entre 10 e 16 horas de trabalho em que não há tempo para os filhos; de outro, oito horas de trabalho num sistema em que as crianças não serão negligenciadas e receberão a educação e o treinamento necessários... (OWEN, 1991, p. 159-169 passim). O que outras utopias apenas indicavam, Owen estabelecia como base para uma reforma possível.

Como o "owenismo" tornou-se um movimento anglo-americano, a idéia de comunidade ganhou força nos dois lados do Atlântico. Nos Estados Unidos, existiram sete comunidades (e mais três das quais os owenistas participaram incidentalmente), das quais há pouca documentação, com exceção de New Harmony, fundada no estado de Indiana em terras compradas de rapistas, que durou de 1825 a 1828. A documentação é mais escassa para Wanborough, no Illinois, que funcionou apenas no ano de 1825; a comunidade de Blue Spring, em Indiana (ano de 1826); Kendall, em Ohio, no mesmo ano; e Yellow Springs, também em Ohio (1825); Valley Forge, na Pennsylvania (1826) e Nashoba, no Tennessee (1825).

Nos Estados Unidos, Owen enfrentou uma série de dificuldades e, de modo geral, todos os críticos às colônias existentes (não apenas as

24 O título, novamente, é evidente: Um esboço dos erros e males derivados do estado presente e passado da sociedade, com uma explanação sobre algumas vantagens especiais que derivam de estabelecer as classes trabalhadoras desempregadas em aldeias de cooperação mútua limitadas a uma população de 500 a 1500 pessoas. OWEN, R. A new view of society and other essays. London: Penguin Books, 1991 (1817-26). p. 159. 
owenistas) exigiam que as mesmas não funcionassem como cidades normais, ou seja, que rejeitassem os estabelecimentos comuns a qualquer cidade (bares, por exemplo) para atingir o ideal prometido. Nos Estados Unidos, depois do período de 1825 a 1829, o movimento owenista ficou dormente; renasceria num novo boom comunitarista nos anos 40 , especialmente de inspiração fourierista, quando quatro novas comunidades foram fundadas: Promisewell, na Pennsylvannia, pela chamada Society of ne-mentians (tinham esse nome por causa da frase de São Pedro para divulgação da fé "be ye of one mind"); Skaneateles, em Nova York; Equality em Wisconsin - esta formada por imigrantes ingleses sob liderança de Thomas Hunt, um cartista owenista de Londres); e Goose Pond, também na Pennsylvania. Pode-se afirmar que todas as comunidades são claramente owenistas, mesmo quando Owen não estava diretamente ligado a elas. Entretanto, muitos outros experimentos comunitários, seculares e religiosos ocorreram (e muitos mais foram projetados, embora nunca empreendidos). Na América, antes da Guerra Civil, podia-se identificar cerca de 130 comunidades com afinidades owenistas. ${ }^{25}$

Os registros sobre tais comunidades "perdidas" é lacunar, pois de certo modo elas duraram poucos anos; tiveram, contrariamente a seus objetivos, um impacto pequeno sobre a sociedade e, se comparadas com outros métodos para a reforma social, podem mesmo parecer um fracasso. Certamente é o que se objetiva quando se adiciona o adjetivo "utópico" a tais experimentos.

Já na Inglaterra, as tentativas de comunidades foram muitas, sendo lamentável que Owen seja comumente identificado apenas com New Lanark. Em 1821, uma cooperativa fora formada em Londres por gráficos (Cooperative and Economical Society), para estabelecer uma comunidade owenista, criando um sistema de produção em Spa Fields, onde os operários dividiam os custos de vida trabalhando nos mesmos empregos, com suas 21 famílias (o que fizeram até o ano de 1823). Outro esquema semelhante, a ser implantado em Motherwell (Lanarkshire), em 1822, nem começou; mas aquele que o concebeu, Archibald James Hamilton, juntamente com Abram Combe, criou a Orbiston Community de 1825 a 1827, que só desa- 
pareceu com a morte de Combe. Uma substancial comunidade existiu em Talahine, Irlanda, entre 1831 e 1833, quando um jovem fidalgo, John Scott Vandeleur, transformou seus 618 acres de terra em uma cooperativa sob a direção de E.T. Craig, o famoso owenista de Manchester. Craig também estava presente na comunidade de Manea Fen, em Cambridgshire, em 1838. Outra de breve duração foi a comunidade owenista de Pont Glas, em Merionetshire em 1840, por owenistas de Liverpool; além de uma comunidade galesa em Garnlwyd, Carnarthenshire, dirigida pela Leeds Redemption Society de 1847 a 1855 . No entanto, o maior esforço owenista ocorreu em Queenwood (chamada de Harmony Hall) em East Tytherly, Hampshire, de 1839 a 1845 (Fabian Tract, n. 166, 1920).

Tentativas semelhantes ocorreram em solo francês, onde, segundo Benevolo, as origens do pensamento urbanístico moderno estão nos anos pós-guerra e na Restauração, em que a especulação teórica busca realizar as promessas frustradas da revolução.

Saint-Simon (1760-1825) não possuía exatamente um projeto urbano, mas, ao defender que o objetivo da sociedade é a produção, criou um funcionamento ideal para seu exército do trabalho, em que a higiene e a rentabilidade são as palavras-chave do urbanismo (RAGON, 1975, p. 221). Recuperando de certo modo o pressuposto smithiano de que o enriquecimento capitalista é o principal fator de progresso social, Saint-Simon defende o predomínio da ordem econômica sobre a social, uma vez que os homens não necessitam ser governados, mas administrados. Seu pensamento, porém, tem maior influência sobre a elaboração política - como o estabelecimento de escolas saint-simonistas por seus seguidores - e não origina propostas urbanas ou habitacionais, como ocorreu com Charles Fourier (1772-1837). Este, em seu tratado sobre "uma associação doméstico-agrícola" descreve uma cidade que seria construída no terceiro período, rejeitando a forma do tabuleiro de xadrez, com ruas serpenteadas para evitar a uniformidade, com o fundo das ruas para vistas campestres e monumentos de arquitetura pública ou privada, praças etc. (apud BENEVOLO, 1993, p. 69-70). Centrado na análise das paixões humanas (e não na análise econômica nos termos de Owen e Saint-Simon) e na previsão de uma sucessão de períodos para as realizações humanas, Fourier evoluiria essa primeira descrição para a proposta do Falanstério, cuja realização, embora ensaiada por vários de seus discípulos, como Victor Considerant, jamais chegou a ser realizada durante sua vida. 
O Falanstério, financiado por um particular ou um soberano, seria uma associação para 1500-1600 pessoas, nos arredores de um curso d'água e afastado da cidade. Parcialmente inspirada na distribuição espacial da cidade de Arc-et-Senans, de Ledoux, cada falange em si é uma pequena cidade, composta por ruas cobertas. A comunidade é gerida pelo sistema de cooperativas de produção e consumo dos produtos, não há salário e as crianças são criadas por todos os membros.

Os mais conhecidos Falanstérios realizados (e propagandeados na publicação de Considérant, La Phalange) localizaram-se, respectivamente, em Condé-sur-Vesgres (1834) e Citeaux (1841), além das "tentativas" na região do Saí, no Brasil, e da União Agrícola, na Argélia, próximas ao fim do século XIX. ${ }^{26} \mathrm{O}$ falanstério realizado e existente enquanto estrutura física até hoje é o de Godin, em Guisa, embora a experiência em Brook Farm, nos Estados Unidos (Brisbane), seja notável, bem como tentativas na Rússia, na Argélia e na Nova Caledônia. ${ }^{27}$ No caso de Godin, sua proposta é uma redução da idéia original do Falanstério, criando uma empresa de caráter industrial (e não agricultural), em que cada família tem seu espaço. Chegou, em 1886, a contar com uma comunidade de 400 famílias, considerada a experiência mais feliz no século XIX pelos teóricos do socialismo, baseada na longa duração do experimento.

Uma terceira corrente do pensamento utópico francês, segundo Benevolo (1993), inicia-se com Buonarroti, que inspirou diretamente Étienne Cabet (1788-1856), quem escreveu o romance utópico Voyage en Icarie durante seu exílio na Inglaterra, utilizando sua vasta experiência política de um comunismo integral obtido por meio de persuasão. Tal programa político o fez publicar nos jornais o manifesto "Allons en Icarie", tendo comprado um terreno dos mórmons em Illinois, tentou criar sua Icária-Esperança

26 Sobre o caso brasileiro há alguns trabalhos publicados, como o de THIAGO, R. S. Fourier: esperança e utopia na Península do Sá. Florianópolis: UFSC, 1995.

27 Brook Farm foi uma comunidade experimental fundada em 1841, que, curiosamente, atraiu os intelectuais da Nova Inglaterra. Localizada em West Roxbury, Massachusetts, perto de Boston e fundada por George Ripley, objetivava unir o trabalho físico e o mental, buscando o ideal de uma vida simultaneamente simples e culta. Todos os seus membros, fossem trabalhadores braçais ou intelectuais, recebiam o mesmo salário e os lucros dividiam-se conforme o número de dias trabalhados por cada um. O escritor Nathaniel Hawthorne foi um dos primeiros a ir para tal comunidade, assim como o editor Charles Dana, ao lado de artesãos e fazendeiros. 
(depois cindida em Nova Icária), mas seus planos enfrentaram grande número de cismas e pequeno número de habitantes (muito inferior ao projetado), o que fez com que seu plano, de uma idéia de metrópole notável, se reduzisse a aldeias rurais exíguas. ${ }^{28}$

De modo geral, essas experiências podem ser vistas, a posteriori, como ingênuas, embora tenham sido fonte e reapropriação para o que se seguiu: a nostalgia rural de proximidade com a natureza, as propostas de unidade de habitação, de número limitado de habitantes, de instalações centralizadas, de pátios e ruas internas, todas presentes em muitas das soluções da arquitetura moderna. O número de habitantes do paralelogramo de Owen (1200) e do Falanstério de Fourier (1620) correspondem à unidade de habitação de Le Corbusier e a densidade de Owen, um acre por habitante, é a mesma de Wright para Broadacre City (BENEVOLO, 1993, p. 73-74).

Igualmente significativas, mas geralmente negligenciadas, são as comunidades promovidas por industrias, como as cidades de Saltaire, Port Sunlight, New Earswick e Bournville, descritas (e por vezes inspiradas) por romances, como Le juif errant (1845), de Eugene Sue, inspiração para Saltaire; ou no Les misères des enfants trouvés (1851), do mesmo autor, que retoma os paralelogramos de Owen. Ainda, a localização das fábricas de Oswald Millbank descrita em Coningsby, de Disraeli, lembra a fiação de Styal, enquanto Sybil, or the two nations (1845), do mesmo autor, faz lembrar Saltaire. As cidades de industriais, ao lado de outros experimentos de comunidades, ampliam a compreensão da importância do passado nas definições dos ideais de um século marcado pelo trabalho industrial.

Dentre as mais conhecidas cidades inglesas construídas em função de uma indústria, destacam-se os núcleos fabris de Brombourough Pool (da fábrica de velas Price's Patent Candle Company, 1853), Port Sunlight (da fábrica de produtos de limpeza Lever, 1888), Bournville (da fábrica de cho-

28 Cf. JOHNSON, C. Utopian Communism in France - Cabet and the Icarians, 1839-1851. Ithaca; London: Cornell University Press, 1974. Para Johnson, a utopia de calma felicidade de Cabet, com seu cristianismo em forma primitiva, adequava-se muito mais aos ideais dos trabalhadores que a teoria do progresso de Saint-Simon ou os complicados estágios de Fourier. Já Georges Jean salienta que foi exatamente tal experimento que originou amargas críticas por parte de Proudhon, as quais encabeçariam a condenação de tais experimentos. 
colates Cadbury, 1894), Saltaire (fábrica de fiação concebida por Sir Titus Salt entre 1851 e 1876) e New Earswick (da fábrica de chocolates Rowntree, 1902).

Em seu notável trabalho, Telma Correia observa que as "cidades de companhia" ${ }^{29}$ funcionam como aglomerações isoladas, dependentes de recursos locais (como água para operar os moinhos), inteiramente sob a direção de uma empresa que organiza o espaço ditando as regras de funcionamento, que incluem o trajeto fixo trabalho-casa (CORREIA, 1995, p. 81 et. seq.) e incorporam "equipamentos" em seu interior, como comércio, equipamentos para lazer, cuidados com o corpo (médicos, lavanderias, casas de banho) e proibindo outros equipamentos ( $p u b s$, casas de penhor ou de "má fama").

Todos os núcleos tinham em comum, além do objetivo de fugir dos grandes centros urbanos (mas próximos a eles), o de proporcionarem aos trabalhadores um ambiente de vida que influenciaria definitivamente em seu caráter (conforme o credo de Owen), os estilos de moradia que privilegiavam a habitação integrada a modernos padrões de higiene e salubridade e a presença de espaços verdes. De fato, tal questão alimenta quase todas as descrições e propostas - radicalizada na Higeya, de Richardson (1876), que tem o próprio nome da deusa da salubridade grega; mas também encontrada na cidade de Victoria, de Buckingham (1849), na Icária, de Cabet, (1840) e na Franceville, de Julio Verne (1889). Do mesmo modo, a preocupação com a comodidade dos moradores é constante: Fourier vai imaginar ruas climatizadas, Cabet, calçadas protegidas, e tudo o que lembrasse desordem ou mal funcionamento (jogo, bebida, becos) não encontraria espa-

29 Correia elege a expressão "cidades de companhia" para descrever seu objeto. O presente trabalho opta por "cidades industriais", para evitar o termo acima, que parece cunhado especificamente para o caso americano (Cf. GARNER, 1992, p. 3-4), sendo um modo pejorativo de se referir a cidades de mineração e fundição. Ainda segundo Garner, o tom pejorativo foi abandonado nos termos que se seguiram, especialmente para o caso europeu: "mill towns" (cidades de fiação) ou industrial villages. Optou-se, no presente trabalho, igualmente por evitar os termos "vilas operárias" ou "cidades operárias", que, para a argumentação, não conferem o devido realce à presença do industrial, que concebe tais cidades segundo normas de funcionamento e distribuição espacial evidentes, isoladas de grandes centros, diferentes de vilas surgidas ao redor de fábricas. CORREIA, T. de B. Pedra: plano e cotidiano operário no sertão - o projeto urbano de Delmiro Gouveia. Campinas, 1995. Tese (Doutorado) - Universidade de São Paulo; GARNER, J. S. (Org.). The Company Town: architecture and society in the industrial age. New York; Oxford: Oxford University Press, 1992. 
ço para se realizar, pois a própria pureza do traçado da cidade impediria essa formação. Uma terceira característica a ser lembrada era a proximidade - e o conseqüente desafogamento - dos grandes centros urbanos e industriais: Port Sunlight está próxima a Liverpool e Manchester; Bournville a Birmingham; New Earswick está próxima a York, e Saltaire, próxima a Bradford. $\mathrm{O}$ isolamento não é tanto geográfico como da organização do espaço e de seus habitantes: reforça-se a autoridade única do patrão sobre o grupo isolado, voltado para a atividade da produção. No caso das cidades de Port Sunlight (1888), Bournville (1894), New Earswick (1902) e Saltaire (1867), esse isolamento era bastante relativo, visto que a proximidade com um grande centro industrial era necessária, senão o principal motivo para a fundação da cidade de industrial, que aliviava a pressão sobre a cidade próxima. Bradford, a cidade próxima a Saltaire, teve sua população aumentada em $60 \%$ na década de 1810 , novamente em 1820 e mais uma vez na de $1830 .{ }^{30} \mathrm{Na}$ imagem da cidade (figura 58), o vulto da superpovoada Bradford surge como um aviso do contraponto à ordem concebida por Saltaire.

Tratava-se de construir a Jerusalém em meio aos escuros satânicos moinhos? Fossem vilas operárias dentro de cidades ou cidades-modelo localizadas no campo, os núcleos pertenciam a uma única empresa (ou família) que organizava o espaço e estabelecia a rotina do local. A disponibilidade dos trabalhadores era garantida por uma rotina regrada de trabalho e lazer. Trazia-se, assim, para a vida do operário, domínio semelhante ao que o processo fabril exercia sobre as relações de trabalho. Os muitos críticos a essa empreitada lembram que os industriais nessas condições experimentavam um grau de controle sobre sua força de trabalho semelhante aos donos de fábrica do século XVIII. ${ }^{31}$

Em todos esses experimentos, a exaltação do trabalho e do conhecimento é marcante, em especial porque não somente a fábrica, mas todos os equipamentos a ela associados - como a escola técnica, a igreja, o salão (hall) onde os operários assistem a aulas e palestras - mobilizam-se em torno do tema do trabalho.

30 EVANS, E. J. The forging of the modern state - early industrial Britain 1783-1870. New York: Longman, 1986. p. 153.

31 GASKELL, M. S. Model Housing - from the great exhibition to the festival of Berlin. London: Mansell Publishing, 1987. p. 53. 
O funcionamento das comunidades efetivamente postas em prática, entretanto, variava muito de acordo com a empresa; enquanto alguns núcleos funcionavam mais como abrigos, outros incluíam uma proposta paralela de educação, religião e esporte. A cessão da moradia também ia desde a cessão completa até a venda da habitação após certo tempo de uso ou o aluguel a preços módicos se comparados com os das cidades. Um fato relevante, mas poucas vezes explorado, é que essas cidades não eram, por nenhuma regra estabelecida, moradia somente para os operários da firma. Na década de 1920, um livro sobre Bournville indicava expansão da cidade, iniciada na virada do século, e salientava que, ao final da década de 1910, apenas $41 \%$ dos habitantes da cidade de Bournville trabalhavam na firma Cadbury. ${ }^{32} \mathrm{O}$ dado é surpreendente, pois indica que se concretizava o objetivo de expansão do modelo urbano e atração da população externa, conforme desejara Cadbury.

A aplicação dos princípios de moradia em ambientes controlados ligados a uma indústria deu-se primeiro no vilarejo industrial de Bournville, iniciado em 1879, seguida de perto por Port Sunlight (1888). A sequiência foi sempre a mesma: em primeiro lugar, construía-se a fábrica, logo em seguida, as moradias. Em Bournville, os irmãos Cadbury construíram 143 casas que repassaram em um sistema de leasing por 999 anos (de forma a garantir a preservação da moradia e dos jardins).

As terras ao redor do estabelecimento fabril foram transformadas em ruas arborizadas que evitaram a uniformidade; as moradias, dispostas em grupos de cinco ou seis, em ruas levemente sinuosas. $\mathrm{O}$ arquiteto de Bournville, W. A. Harvey, declarou que era "quase sempre melhor utilizar os contornos naturais (...) do que a linha reta." 33

Das cidades aqui mencionadas, apenas Saltaire seguiu os moldes de grelha. Conforme narram os biógrafos de Sir Titus Salt, o industrial concebeu Saltaire para seus operários (cerca de 400) ao lado de sua indústria têxtil após sua experiência como prefeito de Bradford (1848), em que enfrentou de agitações cartistas a surtos de cólera. A cidade, encomendada

32 GARDINER, A. G. Life of George Cadbury. London: Cassel and Company Ltda., 1923. p. 146.

33 Apud GASKELL, op. cit., p. 54. 
aos arquitetos Lockwood e Mawson, deveria ter "cada instituição que possa melhorar a condição moral, mental e religiosa dos trabalhadores" (BARGARNIE, 1877, p. 135). Saltaire é, em si, um forte investimento personalista: as principais ruas atestam a lealdade à Coroa (Victoria Road, Albert Road e Albert Terrace); a família está presente nas ruas adjacentes, que trazem o nome da esposa, dos filhos, netos e outros membros da família do industrial Titus Salt. O nome dos arquitetos figura nas ruas Lockwood e Mawson. Ao todo, construíram-se 23 ruas, num total de 895 residências (com três dormitórios) espalhadas por 25 acres. Casas de banho, lavanderias e um banho turco completavam os equipamentos urbanos. Havia também unidades asilares, para um total de 75 idosos e/ou enfermos, sendo dada preferência aos que houvessem trabalhado na fábrica. ${ }^{34}$

Os industriais, nas cidades que criavam, procuravam as soluções para os problemas sociais que descreviam. O "sweat-system" preocupava Cadbury (Sweating, [18-]) e a pobreza era o tema de Rowntree, idealizador de New Earswick (Poverty - a study of town life, 1901; Industrial unrest: a way out, 1922 e Portrait of a City's Housing, 1924). Os princípios da baixa densidade, depois utilizados nas cidades-jardim, garantiam as vistas pitorescas ( 5 a 8 casas por acre em Port Sunlight e 7 a 8 em Bournville). O desejo de variedade expressava-se em chalés de aparência rústica, alguns beirando o exagero (como em Port Sunlight).

$\mathrm{O}$ arquiteto Harvey, que concebeu as moradias em Bournville, salientava que a beleza das moradias era obtida não pela ornamentação, mas pela simplicidade, que dava às habitações o aspecto de lar. A economia na construção (telhado contínuo, escadas compartilhadas, pequena banheira recolhível no chão da cozinha) era compensada por vantagens como fogão a gás, prateleiras e armários. Mesmo assim executados, os chalés sempre custaram mais do que os aluguéis poderiam retornar; o que os industriais, como Lever, faziam questão de enfatizar. Esse fator diminuía em muito o número dos industriais dispostos a investir em habitação social; e os experimentos foram, de fato, poucos.

Segundo Garner, nessas cidades, "o paternalismo do proprietário se estendia além das meras necessidades arquiteturais de fábricas e minas.

34 OGDEN, D. Introduction. In: BALGARNIE, R. Sir Titus Salt, baronet: his life and its lessons. (1877). Yorkshire: Brenton Publishing, 1970. p. 6 et seq. 
Casas bem projetadas, parques, escolas, bibliotecas, halls, tudo isso em um cenário atraente, representavam um grau incomum de interesse por parte do proprietário (...)". E arremata: "alguns industriais residentes tinham um interesse genuíno pelo bem-estar de sua força de trabalho, procurando criar um ambiente modelar." ${ }^{35}$

Pode-se afirmar, aceitando a "positividade" histórica do paternalismo, que essas cidades são mais dos industriais que as concebem do que das indústrias: a permanência da figura do industrial e da figura benemérita de sua esposa - como Lady Lever, que batiza e inaugura a galeria de arte em Port Sunlight - aparecem como uma obra de visionarismo e filantropia.

Também na literatura a figura do industrial sobressai, especialmente a de folhetins e romances baratos, que exploravam essa outra forma de se viver. $O$ judeu errante, folhetim de Eugene Sue - no qual, após um clímax que levaria ao final do livro, há um incoerente recomeço da trama (exigência dos editores) -, traz a descrição de um núcleo fabril nos arredores de Paris. Benevolo menciona um breve trecho dessa obra, mas comete uma grande injustiça ao não explorar com mais vagar todo o sistema de funcionamento da cidade de industrial, cuidadosamente explicado em um longo capítulo. ${ }^{36}$

Sue descreve primeiro a habitação do trabalhador Agricola, que mostra a vila ideal para sua convidada Ângela, finalizando com um elogio ao industrial Sr. Hardy.

35 GARNER, op. cit., p. 4.

36 Aliás, quando se menciona a obra de Sue, geralmente se repete o recorte feito pelo próprio Benevolo. Cf. BENEVOLO. As origens da urbanística moderna. Lisboa: Presença, 1987. p. 116. Na verdade, o livro de Sue foi publicado em formato de folhetim nos anos 1844-45, competindo com Alexandre Dumas com seus famosos $O$ s três mosqueteiros e $O$ conde de Monte Cristo. A segunda das maiores séries criadas por Sue (a primeira fora Os mistérios de Paris (1842-43), O judeu errante procede, ao longo de suas centenas de páginas, em uma trama por vezes confusa e contraditória, a comparar de forma alegórica a sina dos trabalhadores com a maldição legendária depositada por Jesus no Judeu Errante (não por menos a Companhia de Jesus é a grande vilã da história). Comparada aos Pickwick Papers de Dickens, essa série foi logo traduzida para o inglês e alguns afirmaram que a descrição da cidade ideal do industrial Mr. Hardy teve profundas influências sobre industriais britânicos como Sir Titus Salt, o criador de Saltaire, e lembra notavelmente a descrição já apresentada das habitações propostas por Owen. 
Os prédios, com face para o sul e o leste, eram rodeados por um grande jardim de cerca de dez acres, parte com um bosque, parte com árvores frutíferas e legumes (...). Antes de continuar com essa descrição que talvez pareça um pouco como um conto de fadas, deixe-nos iniciar dizendo que as maravilhas que estamos prestes a esboçar não devem ser consideradas sonhos utópicos (...) essas maravilhas são resultado de uma especulação excelente, e representaram um investimento tão lucrativo quanto seguro (...). ${ }^{37}$

A boa habitação parece transcender a questão do paternalismo e constituir um bom negócio para o industrial. $\mathrm{O}$ alojamento comum para os solteiros, por um preço extremamente razoável, composto de "uma ante-sala de quarto (...) com chão perfeitamente branco e limpo possui (...) um aquecedor de cama (...) um bom colchão e cobertas quentes (...) nas paredes havia um bonito papel, com as cortinas combinando; uma cômoda, uma mesa, algumas cadeiras, uma pequena biblioteca". Quando o trabalhador deixa seu quarto, pode atravessar corredores limpos e ouvir sons alegres vindos de todos os quartos; em uma oficina trabalham as esposas e filhas de trabalhadores que, não empregadas na fábrica, produzem a roupa de cama e mesa. Com sua convidada, Agricola visita a cozinha comum, onde crianças alegres e concentradas em seu trabalho realizam tarefas nas horas vagas de escola. O segredo do Sr. Hardy está nas palavras Associação - Comunidade - Fraternidade. Os trabalhadores, bem alimentados, agasalhados e com seus produtos adquiridos em sistema de cooperativa, podem chegar, efetivamente, a produzir tanto quanto os trabalhadores ingleses. ${ }^{38}$

Há, logicamente, uma celebração do papel paternal do empresário, mas é exatamente a recuperação de como foi construída essa figura e não seu obscurecimento, que permite compreender o funcionamento de tais cidades ou comunidades.

Pode-se considerar, como o fez Benevolo, o papel assumidamente benevolente de experimentos como o de New Lanark ou aceitar dados que

37 SUE, E. The wandering Jew. Suffolk: Dedalus/Hippocrene, 1990 [1844-45]. p. 550-554 passim.

38 Ibid., p. 555-562 passim. 
indicam condições de vida efetivamente superiores em tais locais. Mas toda a literatura que aborda essas cidades confunde de bom grado o personalismo patente dos industriais que as conceberam com o funcionamento das cidades em si, como se, nelas, os trabalhadores não tivessem criado suas próprias sociabilidades e modos de viver. Nesse sentido, as cidades de industriais são mais do que os industriais que as concebem. Tais considerações, porém, parecem menos importantes do que perceber que a definição de paternalismo industrial para a compreensão desse tipo de experimento generaliza diferentes relações sociais e experiências e limita-se a entender o paternalismo como uma permuta de concessões, por um lado, e obediência, de outro. Certamente, esse sistema que engloba todos os serviços, do aluguel das moradias à saúde, à educação e ao lazer, busca proteger-se da ingerência estatal sobre os próprios negócios. Para Gueslin, a fórmula tripartida que explica esse tipo de paternalismo é a noção de estarem cumprindo um dever pessoal eivado de princípios religiosos - do mesmo tipo que alimentou a filantropia nas grandes cidades; a reabilitação da indústria, que pode reverter aos seus trabalhadores o lado positivo do sistema fabril; e uma forma de conter o movimento socialista, evitando tanto o contato com as idéias perigosas quanto a necessidade de medidas extremas ao proporcionarem uma "boa vida" a seus operários. ${ }^{39}$

Ainda assim, o paternalismo é uma relação e só pode se realizar em via dupla. Cada caso tem um diferente nível de adesão por parte do operário, naquilo que Perrot classificou como uma política mútua de interesses materiais, de segurança e uma aceita convivência com o patrão. ${ }^{40}$

$\mathrm{O}$ fato de que os industriais em pouco alteraram o amplo problema da habitação social na Inglaterra não significa que sua contribuição nos padrões de moradia não tenha sido importante. Como seus ideais iam da melhoria condição de vida das classes trabalhadoras até a expressão em arquitetura dos conceitos de uma vida em comunidade, findaram por criar uma série de soluções urbanas às quais permanentemente se recorre.

Nesse processo, as cidades-jardim britânicas são compreendidas como as últimas herdeiras, em termos de urbanismo, das cidades "ideais"

39 Apud CORREIA, op. cit., 179.

40 PERROT, M. Maneiras de morar. PERROT, M. História da vida privada IV. São Paulo: Cia. das Letras, 1991. p. 307 et seq. 
ao longo do século XIX. São igualmente herdeiras de padrões ambicionados pelas cidades de industriais. New Earswick, da fábrica Rowntree, foi projetada por Unwin e Parker, seguindo os moldes de Letchworth. O arquiteto do Arts and Crafts Movement, William Owen (1846-1910), projetou todos os chalés de Port Sunlight e, quando Parker e Unwin produziram seu livro The Art of Building a Home (1901), fizeram-no inspirados em William Morris, que afirmara que as casas deveriam ser projetadas "de dentro para fora", ou seja, com cômodos grandes o suficiente para serem habitados, saudáveis e confortáveis (apud CUMMING; KAPLAN, 1993, p. 62). Os congressos que lançaram a Garden City Association, sintomaticamente sediados em Bournville (1901) e Port Sunlight (1902), contaram com o total apoio (e doações) dos industriais Cadbury e Lever. ${ }^{41}$ Sistemas para manutenção dos jardins, como os existentes em Cadbury, foram inicialmente adaptados nos regulamentos internos das cidades-jardim. Por exemplo, em Bournville, os moradores eram responsáveis pela manutenção dos jardins, pois, acreditava-se, delegar completamente essa função a outros fazia com que os moradores não pudessem apreciar o valor dos jardins nem ter o prazer de lidar com a terra. Mas havia um "Departamento de Jardins" que emprestava ferramentas aos moradores, vendia sementes, supria a biblioteca com livros sobre jardinagem, ministrava aulas para homens e garotos e promovia uma exposição anual de flores. ${ }^{42}$

Em News from Nowhere, o viajante para o futuro observava, encantado: "A Inglaterra é agora um jardim" (MORRIS, 1993, p. 105). E as propostas para se transformar a cidade em jardim, tendo como objetivo reestruturar o ambiente em padrões especificamente rurais, traduzem-se tanto na criação dos subúrbios quanto nos planos de cidades ideais.

O juízo que o movimento marxista expressa sobre os movimentos utópicos é o de que estes desperdiçavam importante energia, procurando

41 Uma vez que o tema das cidades-jardim constituiria um trabalho em si e que a bibliografia sobre o tema é bastante vasta e pertinente, é apenas desse prisma de continuidade (continuidade essa almejada na própria constituição das cidades-jardim) que tais cidades são destacadas no presente artigo. Para análises bastante completas, ver: FISHMAN, R. Urban utopias in the twentieth century. New York: Basic Books, 1977; BUDER, S. Visionaries and planners - the garden city movement and the modern community. Oxford: Oxford University Press, 1990; e BEEVERS, R. The garden city utopia - a critical biography of Ebenezer Howard. London: Macmillan Press, 1988.

42 GARDINER, op. cit., p. 180. 
atingir os objetivos da reforma social pelos meios pacíficos das experiências em pequena escala. Benevolo também considera que as soluções sugeridas por tais grupos para o problema da cidade

...são abstratas e esquemáticas, na medida em que falta uma avaliação realista dos vínculos entre os programas urbanísticos e o desenvolvimento geral das relações econômicas e sociais, facultando a ilusão de que a ordem urbanística e a ordem social se identificam entre si, e a segunda pode ser construída com os tempos e os métodos da primeira. ${ }^{43}$

Fica evidente que ele concorda com a postura de Engels de que o Estado ou o empreiteiro, ao cederem uma casa ou fazerem com que seja comprada pelo sistema de poupança, não livram o operário da exploração capitalista; isso apenas permite ao capitalista extrair do salário o que corresponderia ao aluguel e diminuir a mobilidade do trabalhador, ou seja, sua autonomia perante o que é estabelecido por aquele que o emprega. Assim, os slums eram apenas deslocados pelas tentativas filantrópicas e não eliminados.

Para Benevolo, todas essas as experiências levam à experiência recente da urbanística, sendo fundamental absorver a questão da habitação dentro da questão social, pois

...tal como as propostas técnicas dos utopistas puderam ser dissociadas das inovações sociais e utilizadas pelo reformismo paternalista para conservar precisamente a ordem social ameaçada pela revolução, também as iniciativas promovidas pelas forças conservadoras, uma vez traduzidas em realidade, puderam ser desenvolvidas em sentido contrário à motivação política de partida, e em seguida transformadas em armas para derrubar o sistema conservador. ${ }^{44}$

43 BENEVOLO, op. cit., p. 93-94.

44 Ibid., 154 
Engels o dissera com clareza: um “(...) socialismo eclético e medíocre (...) uma mistura extraordinariamente variegada e cheia de matizes, compostas de desabafos críticos, princípios econômicos e (...) imagens sociais do futuro", sendo necessário, para converter o socialismo em ciência, "antes de tudo, situá-lo no terreno da realidade." ${ }^{45}$ Mesmo parte do romance social, quando menciona esses experimentos, pouco confia neles como a solução dos problemas. A fábrica do industrial Mr. Trafford, no texto de Disraeli, localizada na zona rural, é descrita como salubre, assim como a pequena cidade adjacente - suas casas, seus pequenos jardins, a sociedade de horticultura de competição (assim como em Saltaire). Mas o personagem Morley afirma que "não todos os homens agirão como o Sr. Trafford, pois isso exige um sacrifício de si que não é natural. E completa afirmando que não é a influência individual que vai renovar a sociedade, mas algum novo princípio que vai reconstruí-la". Por certo, Disraeli não tinha em mente nenhuma nova ordem social, como revela mais adiante, dizendo que a solução para Mowbray estava em reavivar a bela catedral gótica e reencontrar o Deus agora tão desconhecido. A personagem Mary Barton, de Gaskell, encontra um final diferente: casada com Jem Wilson, trabalhador fabril como ela, parte para uma nova vida no Canadá. A promessa de felicidade estava em outro lugar, no Novo Mundo. Assim como Disraeli, Gaskell utiliza uma personagem, Job Legh, para preconizar que a solução era que patrões e empregados buscassem pacificamente o interesse comum, dentro do espírito cristão. Até mesmo Dickens, em seu Tempos difíceis, finaliza a obra afirmando que enquanto os homens não aprenderem a amar uns aos outros, $o$ aterrador poder de Coketown persistirá.

Contrariamente, a definição de utopia já tornada célebre por $\mathrm{K}$. Manheim estabelece a utopia como algo mais que uma incongruência voltada para objetivos que não existem na realidade. As utopias são orientações que, uma vez transformadas em condutas, podem abalar parcial ou totalmente a ordem das coisas (uma função revolucionária que abala o status $q u o$ ). Ou seja, todas as idéias que não correspondem imediatamente à ordem concreta dos fatos podem receber a denominação de utopias, uma vez

45 ENGELS, F. Do socialismo utópico ao socialismo científico. In: Textos 1 - Karl Marx e Friedrich Engels. São Paulo: Edições Sociais Ltda., 1975. p. 37. 
que, segundo Manheim, a utopia é irrealizável apenas do ponto de vista de uma dada ordem social vigente, o que não significa que seja inviável em qualquer ordem. Afinal, a realidade considerada não é aquela em si mas a "concreta, histórica e socialmente determinada, que se acha em um constante processo de mudança." 46

De fato, parece que o pensamento que classifica esses experimentos ainda se vê turvado pela idéia de que em todo Éden há uma serpente que pode trazer seu esfacelamento. Assim, os problemas internos, de gerenciamento, de dinheiro - e até outros acontecimentos como os freqüentes incêndios que prejudicaram as colônias americanas - parecem todos fazer o papel do mal infiltrado no sonho utópico. Essa aproximação, com certeza, prejudica o entendimento da questão. Como afirmado, classificar $a$ posteriori tais experiências como ingênuas impede observar como seus princípios foram, e são, reapropriados dentro da disciplina do urbanismo.

Entretanto, dentre todas as utopias exaustivamente sonhadas e que ficaram apenas em páginas de livros - talvez de onde provenha a pecha de irrealidade -, essas cidades efetivamente foram criadas, habitadas à sombra das empresas e subsistem até hoje, habitadas, porém visitadas como locais turísticos e consideradas como um "espaço-santuário", rodeado por cidades vorazes e modernas. Concebidas como a continuação edificada do industrial e de sua família, por sua vez engrandecidos pelo investimento, prosseguem sendo, em termos de condições de habitação, absolutamente diversas das demais cidades. Certamente os efeitos duradouros que o "reformismo paternalista" surtiu merecem ser mais bem analisados.

De modo geral, a comunidade ideal planejada como contraponto à cidade industrial recai não apenas na comparação física das habitações ou no regramento das atividades, mas na possibilidade do desenvolvimento de uma vida moral, saudável e realizável.

Todo o debate que envolve a casa do operário criada pelo industrial parece seguir sempre o mesmo percurso: a descrição do local, de seu funcionamento, coroado pela denúncia dos objetivos de controle social e moral inerentes ao "patrão", transformado em um capitalista inteligente que consegue lucrar com o tipo de moradia estabelecido e, ao mesmo tempo, 
criar a imagem de filantropo esclarecido tão cara às classes médias do século XIX. É certo que a questão do controle faz parte evidente da criação desses núcleos (com suas regras estabelecidas, como o álcool banido em Saltaire ou o incentivo, quase uma obrigação, à apreciação das artes em Port Sunlight). É preciso estar atento, porém, para que, com essa denúncia, não se repita um discurso já da época, qual seja, a do patrão que utiliza todos os meios para controlar seu trabalhador. Isso parece impingir a essas comunidades o que seus idealizadores obviamente jamais procuraram estabelecer: que houvesse alguma possibilidade de minar o capitalismo ou a realidade industrial.

Todos os projetos de vida comunitária em função de uma empresa investem exatamente na capacidade produtiva de seu trabalhador e na capacidade de venda e manutenção da empresa. As comunidades operárias industriais aceitam a realidade da Revolução Industrial e buscam "humanizála" em termos de padrões de vida e de trabalho contrapostos aos horrores tão minuciosamente descritos da vida nas grandes cidades. $\mathrm{O}$ retorno à pequena aldeia, também ligado à nostalgia medievalista do período, está mais fortemente baseado na idéia da guilda que na do comunismo. Comunitários, ou amplamente compartilhados, seriam os parques, os produtos da horta, a tarefa de educar as crianças, mas não os resultados - e o salário obtidos na lida diária. Os objetivos de uma educação mais ampla e do acesso aos textos clássicos existiam não apenas nessas cidades, mas também nos grandes centros industriais por meio das Fraternidades de operários, esclarecidos por meio de lectures, promovidas até mesmo pelos movimentos de trabalhadores e movimentos sindicais os mais combativos.

Acusar os empresários idealizadores dessas cidades de assim as conceberem, como se fora sua obrigação apontar para a saída do socialismo em contraposição ao socialismo utópico, parece uma via absurda muitas vezes trilhada pelos comentários sobre esses experimentos. A cidade utópica, comunidade ideal ou model village, é o reverso da medalha em um momento caótico de organização do trabalho e do espaço urbano. Surge como sonho possível, que ainda alimenta o urbanismo de inspiração inglesa (as cidades-jardim) de um lugar que, diferentemente do sugerido pelo "não-lugar" - utopia -, pôde de fato ser criado e habitado. 


\section{Referências}

BACON, F. Nova Atlântida. Lisboa: Minerva, 1976.

BACZKO, B. Lumières de l'utopie. Paris: Payot, 1978.

BEEVERS, R. The garden city utopia - a critical biography of Ebenezer Howard. London: Macmillan press, 1988.

BENEVOLO. As origens da urbanística moderna. Lisboa: Presença, 1987.

BLAKE, W. Prosa e poesia selecionados. Tradução e prefácio de Paulo Vizioli. São Paulo: Nova Alexandria, 1993. Edição Bilíngüe.

BUDER, S. Visionaries and planners - the garden city moviment and the modern community. Oxford: Oxford University Press, 1990.

CHOAY, F. A regra e o modelo: sobre a teoria da arquitetura e do urbanismo. São Paulo: Perspectiva, 1985.

CORREIA, T. de B. Pedra: plano e cotidiano operário no sertão - o projeto urbano de Delmiro Gouveia. Campinas, 1995. Tese (Doutorado) - Universidade de São Paulo.

ENGELS, F. Do socialismo utópico ao socialismo científico. In: Textos 1 - Karl Marx e Friedrich Engels. São Paulo: Edições Sociais Ltda., 1975.

EVANS, E. J. The forging of the modern state - early industial Britain 1783-1870. New York: Longman, 1986.

FILARETE. Cadernos: clássicos do urbanismo. Tradução de Ivone Salgado e Mário Henrique Simão d'Agostinho. Campinas: Curso de Especialização em Urbanismo, FAU-Puccamp, [19-].

FISHMAN, R. Urban utopias in the twentieth century. New York: Basic Books, 1977.

GARDINER, A. G. Life of George Cadbury. London: Cassel and Company Ltda., 1923.

GARNER, J. S. (Org.). The Company Town: architeture and society in the industrial age. New York; Oxford: Oxford University Press, 1992.

GASKELL, M. S. Model Housing - from the great exhibition to the festival of Berlin. London: Mansell Publishing, 1987.

GIRARDET, R. Mitos e mitologias políticas. São Paulo: Cia. das Letras, 1987. 
JEAN, G. Voyages en utopie. Paris: Gallimard, 1994.

JOHNSON, C. Utopian Communismn in France - Cabet and the Icarians, 18391851. Ithaca; London: Cornell University Press, 1974.

LÖWY, M.; SAYRE, R. Revolta e melancolia - o romantismo na contramão da modernidade. Petrópolis: Vozes, 1995.

MANHEIM, K. Ideologia e utopias. Rio de Janeiro: Zahar, 1972.

MORE, T. A utopia. In: MORE, T. Os pensadores. SãoPaulo: Martins Fontes, 1993.

MORRIS, W. News from Nowhere and other writtings. London: Penguin Books, 1993.

OGDEN, D. Introduction. In: BALGARNIE, R. Sir Titus Salt, baronet: his life and its lessons. (1877). Yorkshire: Brenton Publishing, 1970.

OWEN, R. A new view of society and other essays. London: Penguin Books, 1991.

OWEN, R. A view of a plan of the agricultural and manufacturing villages of unity and mutual co-operation. Morning Post, 7 Aug. 1817.

PERROT, M. Maneiras de morar. In: PERROT, M. História da vida privada IV. São Paulo: Cia. das Letras, 1991.

ROSENAU, H. The ideal city. London: Routledge/Kegan Paul, 1959.

SENNETT, R. Carne e pedra - o corpo e a cidade na civilização ocidental. Rio de Janeiro: Record, 1997.

SUE, E. The wandering Jew. Suffolk: Dedalus/Hippocrene, 1990.

SWIFT, J. Viagens de Gulliver. Rio de Janeiro: W. M. Jackson, 1964. (Clássicos Jackson, v. 31).

SZACKI, J. As utopias ou a felicidade imaginada. Rio de Janeiro: Paz e Terra, 1972.

THIAGO, R. S. Fourier: esperança e utopia na Península do Sá. Florianópolis: UFSC, 1995.

WILLIAMS, R. O campo e a cidade na História e na Literatura. São Paulo: Cia. das Letras, 1990. 